\title{
O NÍVEL INVESTIGATIVO DAS ATIVIDADES EXPERIMENTAIS PROPOSTAS EM LIVROS DIDÁTICOS DE CIÊNCIAS DO ENSINO FUNDAMENTAL ${ }^{1}$
}

\author{
THE INVESTIGATIVE LEVEL OF EXPERIMENTAL ACTIVITIES PROPOSED \\ IN SCIENCE TEXTBOOKS FROM THE ELEMENTARY SCHOOL
}

\author{
Gabriela Rodrigues da Cunha² e Márlon Pessanha ${ }^{3}$
}

\section{RESUMO}

O livro didático serve de fonte de conhecimento, exercícios, atividades e referência para professores. O PNLD estipula critérios que devem ser contemplados, o que incluem alguns relacionados com as atividades experimentais presentes nos livros. Neste artigo, apresentamos um estudo sobre o nível investigativo de propostas de atividades experimentais presentes em livros didáticos de ciências do Ensino Fundamental. Em nosso estudo centrado em quatro atividades, verificamos um baixo grau de investigação, sem situações problematizadoras que envolvam os alunos, com roteiros fechados a serem seguidos, e com uma indicação de participação limitada, passiva e, em certa medida, mecânica dos alunos. Julgamos importante que novos estudos sejam realizados, buscando revelar o papel e nível investigativo de outras atividades experimentais presentes em livros didáticos de ciências.

Palavras-chave: atividades experimentais, participação dos alunos, nível investigativo.

\section{ABSTRACT}

The textbook serves as a source of knowledge, exercises, activities and a reference for teachers. The PNLD stipulates criteria that must be considered, which include some related to the experimental activities. We present a study on the investigative level of proposals for experimental activities present in elementary science textbooks. In our study centered on four activities, we found a low degree of investigation, with no problematic situations involving the students, with closed scripts to be followed, and with a limited, passive and, to a certain extent, mechanical participation of the students. We believe it is important that new studies are carried out, seeking to reveal the role and investigative level of other experimental activities present in science textbooks.

Keywords: experimental activities, student participation, investigative level.

1 Artigo científico.

2 Laboratório de Práticas e Atividades Didáticas - Universidade Federal de São Carlos. E-mail: cunhargaby@gmail.com 3 Departamento de Metodologia de Ensino - Universidade Federal de São Carlos. E-mail: marlonpessanha@yahoo.com.br ou pessanha@ufscar.br 


\section{INTRODUÇÃO}

Desde a sua inserção na educação básica, a disciplina de ciências teve, no livro didático, um dos seus principais pontos de apoio, em especial para os professores. Conforme destacam Fracalanza e Megid Neto (2006), os livros didáticos são utilizados como fonte primária de conhecimento e de referência de pesquisa por professores, servindo de base para seleção e organização de currículo, fonte de exercícios e atividades em sala de aula e referência metodológico-pedagógica. Além disso, o livro didático acaba por constituir mecanismos de mediação entre o conhecimento escolar e o conhecimento científico.

Desde o Século XX, o ensino de ciências vem sendo concretizado por meio de diferentes modelos pedagógicos, representados nas práticas realizadas em sala de aula e nas propostas presentes nos livros didáticos, que assumem diferentes perspectivas sobre como se dá o desenvolvimento de atividades cientificas: Modelo Tradicional; Modelo Redescoberta; Modelo Tecnicista; Modelo Construtivista; Modelo Ciência-Tecnologia-Sociedade (CTS); Modelo Sociocultural (MIZUKAMI1, 1986; AMARAL, 2000; RICARDO, 2007; FERNANDES; MEGID NETO, 2017).

Desde a perspectiva empirista exclusiva, presente nos modelos de redescoberta e tecnicista, que entendemos ser inadequada (PÉREZ et al., 2001), até em perspectivas mais dialógicas que ressaltam a dimensão intersubjetiva da ciência, presentes nos modelos CTS e Sociocultural, a experimentação é reconhecida como parte do fazer científico. Neste sentido, é comum e é esperado que livros didáticos possuam, entre as suas propostas de atividades, aquelas baseadas no desenvolvimento de experimentos. Estas atividades podem se configurar a partir de diferentes níveis de potencial investigativo e de participação dos alunos, de modo que podem desde reforçar visões simplificadas, passivas e tradicionais de ensino e de ciência, até contribuir com o compartilhamento de visões mais adequadas do fazer científico e com processos educacionais mais potenciais em termos de aprendizagem.

Considerando isso, neste artigo apresentamos um recorte de um estudo mais amplo que teve como objetivo analisar atividades experimentais apresentadas e propostas em um livro didático de ciências direcionado aos anos iniciais do Ensino Fundamental. No recorte que aqui trazemos, buscamos identificar os níveis de investigação e participação potenciais em atividades experimentais específicas previstas em um livro didático utilizado por escolas localizadas em uma cidade do interior do estado de São Paulo.

\section{LIVROS DIDÁTICOS NO BRASIL E O PNLD}

No Brasil, a criação do Instituto Nacional do Livro - INL, em 1929, representa um marco da organização nacional em torno da legitimação e do auxílio à produção, no território nacional, de livros, enciclopédias, dicionários, assim como o incentivo à organização e o auxílio à manutenção de 
bibliotecas públicas. O INL se responsabilizava pelas edições, pelas publicações e pela circulação de livros no território nacional, conforme previa o Decreto-lei $N^{o}$ 93, de 21/12/1937, emitido, no período do Estado Novo (1937-1946), pelo então presidente Getúlio Vargas e pelo seu ministro da Educação e da Saúde Pública, Gustavo Capanema (BRASIL, 1937; BRAGANÇA, 2009; FILGUEIRAS, 2011; 2013).

Conforme destaca Bragança (2009), apenas cerca de um ano após a criação do INL, o decreto-lei $n^{\circ} 1006$ de 1938 impôs que a educação fosse realizada com a utilização de livros. O referido decreto-lei (BRASIL, 1938) estabeleceu as condições de produção, importação e utilização do livro didático a serem utilizados nas escolas brasileiras, na educação básica, estabelecendo que somente os livros autorizados poderiam ser utilizados. Ademais, o decreto-lei instituiu a Comissão Nacional do Livro Didático, que seria responsável, entre outras funções, pela análise e julgamento dos livros didáticos quanto à autorização para o uso nas escolas. Este controle sobre os livros didáticos era justificado, conforme discute Filgueiras (2013), pelo fato de não haver, até então, uma regulamentação federal, o que fazia com que cada estado estabelecesse seus próprios critérios, assim como permitia que livros de baixa qualidade ou pouco adequados fossem utilizados.

Filgueiras (2011) afirma que, nas décadas seguintes à criação da Comissão Nacional do Livro Didático, o debate sobre a produção, fiscalização e uso dos livros didáticos continuou, com destaque para a criação da Campanha Nacional de Material de Ensino (CNME), em 1956, e o Grupo de Estudos da Indústria do Livro (GEILPE), em 1959. Já em 1966, a partir de um acordo entre o Ministério da Educação (MEC) e a Agência Norte-Americana para o Desenvolvimento Internacional (Usaid), é criada a Comissão do Livro Técnico de Livro Didático (Colted), responsável por coordenar as ações de produção, edição e distribuição do livro didático no país, dispondo de financiamento governamental para tal. As atribuições e a gestão dos recursos financeiros da Colted passariam, em 1971, ao INL, que elaboraria o Programa do Livro Didático para o Ensino Fundamental (PLDEF). Este programa, por sua vez, foi substituído em 1985 pelo Programa Nacional do Livro Didático (PNLD), criado por meio do decreto $\mathrm{n}^{\circ} 91.542$, de 19 de agosto de 1985 (BRASIL, 1985), o qual prevê a distribuição dos livros escolares aos estudantes matriculados nas escolas públicas, a participação, análise e indicação das obras pelos professores e a reutilização do livro didático (BRASIL, 1985; FILGUEIRAS, 2011).

No âmbito do PNLD, somente a partir de 1996 o Ministério da Educação iniciou o processo de avaliação de obras didáticas inscritas no programa, o que foi estabelecido visando assegurar a qualidade das obras adotadas pelas escolas (FILGUEIRAS, 2011). Segundo Fracalanza e Megid Neto (2006), essa avaliação, que ocorre até hoje com periodicidade trienal, favoreceu o progresso da produção editorial nacional. A partir de critérios que consideram a adequação metodológica, a utilização da linguagem correta e de conteúdo atualizado, a precisão conceitual, a valorização do conteúdo integrado, entre outros, os livros didáticos positivamente avaliados diminuíram significativamente a quantidade de erros conceituais considerados graves. 
No caso dos livros didáticos de Ciências, o PNLD analisa os livros considerando a proposta pedagógica; os conhecimentos e conceitos; a pesquisa, experimentação e prática; a cidadania e a ética; as ilustrações, diagramas e figuras; e o manual do professor (BRASIL, 2008). No que se refere ao critério de pesquisa, experimentação e prática, o PNLD (BRASIL, 2014, p. 65-66) avalia se as propostas buscam estimular a investigação científica, com orientações de atividades experimentais factíveis e com resultados confiáveis, e com orientações claras e precisas sobre o risco envolvido nos experimentos.

No mesmo sentido, a Base Nacional Comum Curricular (BNCC) prevê que o ensino de ciências promova situações em que os alunos tenham condição de observar o mundo e fazer perguntas, analisar demandas e problemas, além de realizar e planejar experimentos. Além disso, a BNCC prevê que os alunos se envolvam em processos em que há o levantamento de ideias e dados, assim como a análise e a representação, sendo ainda capazes de, baseados nesses dados e ideias, articular e discutir conhecimentos, comunicando por diferentes meios suas conclusões (BRASIL, 2018, p. 324).

Reconhecemos que os critérios utilizados na análise das obras submetidas ao PNLD são relevantes e, continuamente, proporcionam um aperfeiçoamento dos livros didáticos. Contudo, percebemos que alguns aspectos, como aqueles previstos na própria BNCC e já discutidos há alguns anos na literatura em educação em ciências, podem não ser suficientemente tratados com base nestes critérios, sendo necessário que se avance um pouco mais na análise e discussão desde o ponto de vista da natureza investigativa da ciência e sua relação com o ensino de ciências. Esse aprofundamento, nos parece, é especialmente pertinente quando se trata das propostas de atividades experimentais, as quais podem se configurar ou não como investigativas.

\section{ATIVIDADES EXPERIMENTAIS E INVESTIGAÇÃO NO ENSINO DE CIÊNCIAS}

As atividades experimentais surgem com o desenvolvimento da Ciência Moderna (MORI; CURVELO, 2017). O filósofo Francis Bacon (1561-1626) foi um dos principais autores da ciência moderna que tratou da experimentação, contribuindo para o estabelecimento de uma linha empirista na ciência, a qual permeia visões sobre a atividade científica até os dias atuais.

Em sua concepção de método indutivo, Francis Bacon assumia que o conhecimento científico devia se construir tendo como base a experiência sensível, empregando um método científico indutivo e rigoroso. Para ele, a partir da observação da natureza deviam ser coletados dados, os quais deveriam ser organizados de forma racional, levando a explicações gerais ou a hipóteses, as quais poderiam ser comprovadas a partir da reprodução sucessiva da experimentação (CHALMERS, 1993). Este método, longe de ser o único na ciência, acaba por ser reproduzido frequentemente, até mesmo em livros didáticos, como "o método da ciência".

A crítica e/ou oposição ao método indutivo e ao empirismo foi feita por diferentes pensadores contemporâneos de Bacon, assim como outros que viveram nos séculos seguintes. No próprio surgimento 
da ciência moderna, o filósofo René Descartes (1596-1650), em seu ceticismo metodológico, entendia que o conhecimento deveria se construir a partir de processos racionais, segundo um processo dedutivo. Para Descartes, a razão (e não a experiência) se ocuparia de verificar se há evidências para algo que é estudado, a partir de uma análise envolvendo a separação e agrupamento de diferentes partes de uma ideia/conhecimento em um todo que se mostrasse verdadeiro, gerando princípios e conclusões (CHALMERS, 1993).

Além de visões restritamente empiristas indutivistas ou racionalistas dedutivistas, representadas respectivamente nas ideias de Bacon e Descartes, outros autores apresentaram e discutiram compreensões de ciência que não se apegavam ao exclusivismo destas vertentes. Aquele que primeiro, talvez, alcançou maior destaque em trazer um posicionamento não exclusivista foi o filósofo Immanuel Kant (1724-1804) que, em seu idealismo transcendental, assumia que mesmo a construção de conhecimento que ocorria a partir da experiência, se dava a partir do enquadramento do novo às estruturas mentais já existentes (MELLADO; CARRACEDO, 1993).

Ao longo do século XX, vários outros autores trouxeram um novo olhar sobre a produção da ciência e o papel dos experimentos. Filósofos da ciência como Karl Popper e Mario Bunge afirmavam que há um método hipotético-dedutivo na ciência, em que as hipóteses são construídas racionalmente a partir de teorias, e são comprovadas (ou não) na experimentação (SILVEIRA, 1989; PIETROCOLA, 1999). Já Gaston Bachelard, outro filósofo da ciência, assumiu um olhar mais englobante a partir de uma reflexão sobre a ciência do século $\mathrm{XX}$, isto é, não restrito e que ia além dos limites do positivismo, do formalismo, do empirismo, idealismo, do racionalismo, etc. Conforme destaca Rheinberger (2005), Bachelard expressava uma dialética no fazer científico, ao assumir que havia um racionalismo aplicado (razão aplicada nos experimentos e no mundo) e um materialismo racional e técnico (realidade material interpretada e criada tecnicamente e teoricamente).

As diferentes visões sobre o fazer científico mobilizaram, na pesquisa em ensino de ciências, reflexões sobre as formas de ensino, sobre as abordagens e estratégias a serem realizadas, além de influir em um olhar mais crítico sobre a atividade experimental que pode ser desenvolvida em sala de aula (MELLADO; CARRACEDO, 1993; PÉREZ et al., 2001). As atividades experimentais passam a ser discutidas quanto ao seu papel, às formas com que são realizadas relacionadas com os níveis de investigação, assim como quanto ao papel dos alunos em meio as etapas de um processo investigativo.

Araújo e Abib (2003), ao tratar dos tipos de atividades experimentais presentes no ensino de ciências, afirmam que elas podem ser atividades de demonstração, de verificação ou de investigação. Enquanto na demonstração, as atividades possibilitam a ilustração de aspectos dos fenômenos, permitindo aos alunos referenciar ideias e noções em algo concreto e perceptível, na verificação busca-se confirmar ou validar leis ou teorias que são estudadas, prática que reconhecemos ser comum no ensino experimental praticado no Ensino Médio e no Ensino Superior, e menos frequente no Ensino Fundamental. Já as atividades experimentais de investigação, que a nosso ver são mais próximas da prática científica, envolvem processos de resolução de problemas, com a elaboração 
de hipóteses, envolvendo observação e descrição de fenômenos, além da elaboração e reelaboração de ideias e explicações.

Ao reconhecer essas três funções que podem ser assumidas por uma atividade experimental, Oliveira (2010) apresenta, para cada uma das funções, os papeis que o professor e os alunos assumem, assim como as características que teriam um roteiro de atividade experimental. O quadro 1, a seguir, apresenta uma adaptação a partir daquilo apresentado pela autora:

Quadro 1 - Papéis do professor, alunos e características dos roteiros de atividade experimental.

\begin{tabular}{|l|l|l|l|}
\cline { 2 - 5 } \multicolumn{1}{c|}{} & \multicolumn{1}{c|}{ Demonstração } & \multicolumn{1}{c|}{ Verificação } \\
\hline \multirow{4}{*}{ Papel do professor } & $\begin{array}{l}\text { Execução do experimento, for- } \\
\text { necendo as explicações do que } \\
\text { ocorre aos alunos }\end{array}$ & $\begin{array}{l}\text { Fiscalização do que é feito } \\
\text { pelos alunos, identificando e } \\
\text { corrigindo erros }\end{array}$ & $\begin{array}{l}\text { Orientação das atividades, } \\
\text { incentivando e questionando os } \\
\text { alunos em suas decisões }\end{array}$ \\
\hline $\begin{array}{l}\text { Atuação como expectadores, } \\
\text { mas em alguns casos podendo } \\
\text { sugerir explicações }\end{array}$ & $\begin{array}{l}\text { Execução do experimento, } \\
\text { explicando o que é observado } \\
\text { e confirmando (ou não) leis ou } \\
\text { teorias }\end{array}$ & $\begin{array}{l}\text { Pesquisa, planejamento e } \\
\text { execução das atividades expe- } \\
\text { rimentais, discutindo possíveis } \\
\text { explicações }\end{array}$ \\
\hline $\begin{array}{l}\text { Roteiro de atividade } \\
\text { experimental }\end{array}$ & $\begin{array}{l}\text { Fechado, estruturado e exe- } \\
\text { cutado exclusivamente pelo } \\
\text { professor (em muitos casos } \\
\text { visível somente a ele) }\end{array}$ & $\begin{array}{l}\text { Fechado, estruturado e executa- } \\
\text { do pelos alunos }\end{array}$ & $\begin{array}{l}\text { Não há um roteiro, ou quando } \\
\text { há, ele é aberto e não é estru- } \\
\text { turado }\end{array}$ \\
\hline
\end{tabular}

Fonte: adaptado pelos autores com base em Oliveira (2010, p. 151)

Atendendo ao objetivo deste trabalho, aprofundamos um pouco mais o olhar sobre as atividades experimentais, buscando detalhar algumas das características que tornam as atividades experimentais investigativas.

Segundo alguns autores, as atividades experimentais investigativas têm como características a proposição e formulação de uma situação problemática; a elaboração de hipóteses; a condução de atividades práticas; o planejamento do experimento e do processo de coleta de dados; as explicações e sistematização dos dados obtidos; e comunicação e discussão dos resultados e conclusões entre os pares durante a investigação (HODSON, 1994; ARAÚJO; ABIB, 2003; SUART; MARCONDES, 2011; ZOMPERO; GONÇALVES; LABURÚ, 2017).

A nosso ver, relacionados as características acima enunciadas, há dois aspectos principais que demarcam uma prática experimental efetivamente investigativa: a existência, de fato, de uma situação problema que orienta o processo experimental; e a participação dos alunos, em níveis mais elevados de autonomia e reflexão crítica, nas diferentes etapas da atividade experimental.

Sobre as situações problema, Astolfi et al. (1997) as definem diferenciando-as da resolução de problemas ou problemas abertos. Segundo os autores, uma resolução de problemas consiste em uma aplicação de conhecimentos teóricos já adquiridos a partir de esquemas e procedimentos de solução voltados para o processo de resolução matemática; já os problemas abertos consistem na apresentação e execução de procedimentos definidos, em meio à interação entre os alunos e mediação do professor 
durante a atividade. As situações problema, por outro lado, consistem em problemas contextuais que demandam o debate científico em sala de aula para uma resolução coletiva, com a elaboração e discussão de hipóteses, e a qual não se resolverá sem que ocorra a aprendizagem em meio ao processo. Os autores ainda afirmam que a situação problema lida com algum tipo de obstáculo de aprendizagem que, a nosso ver, está relacionado com a contra intuição inerente ao conhecimento científico ou com uma situação contextual que de fato se apresenta como problemática e que necessita do conhecimento científico para que haja a solução. No mesmo sentido, Ricardo (2010) argumenta que a problematização, processo inerente ao uso de situações problemas em sala de aula, envolve a observação da realidade elencando, desta, um problema de estudo, aspectos a serem aprofundados e, por fim, a aplicação novamente à realidade. Neste sentido, a realidade contextual é a origem e o fim de uma situação problema, a qual, inevitavelmente, é a fornecedora de uma situação problema que tenha sentido e requeira a solução dos alunos e, ao mesmo tempo, no caso do ensino investigativo apoiado na experimentação, traz um porquê de se fazer a investigação que é proposta.

Vale destacar que as situações problemas, segundo suas características, servem de terreno fértil para a elaboração de hipóteses, com a discussão e desenvolvimento de métodos experimentais, possibilitando ainda uma discussão mais profícua em termos de potencial de articulação de conhecimentos científicos com aspectos presentes no cotidiano dos alunos.

Neste trabalho, em que buscamos analisar as propostas de atividades experimentais em livros didáticos de ciências, a caracterização das situações problema é relevante, em especial, por assumirmos esta noção como um critério para a análise do nível investigativos das atividades experimentais.

Outro critério relevante em nossas análises é o nível de participação dos alunos e dos professores no desenvolvimento das etapas inerentes à atividade experimental. Sobre isso, Araújo e Abib (2003) destacam que em atividades experimentais mais investigativas, os professores são os mediadores, ou seja, os responsáveis por propor questionamentos e auxiliar os alunos na busca por explicações do fenômeno apresentado na atividade experimental de caráter investigativo. Em outras palavras, em uma atividade experimental investigativa, cabe ao professor apoiar os alunos, com a criação de espaços, na disponibilização de materiais, no incentivo por indagações, discussões e argumentações na busca da sistematização do conhecimento.

Já sobre o papel dos alunos nas atividades experimentais investigativas, Suart, Marcondes e Carmo (2009) afirmam que, para além de um trabalho manipulativo ou de observação, que situamos como ações características de atividades demonstrativas e de verificação, na atividade de investigação a participação dos alunos deve ocorrer nas diferentes etapas de investigação, desde na elaboração de hipóteses para a situação problema posta, até na coleta de dados e elaboração de conclusões. Em sala de aula, é de se esperar que as situações propostas permitam aos alunos interagir entre si, argumentando e contra-argumentando na busca de explicações para o que é desenvolvido e verificado a partir dos experimentos. 
Focando-se nas atividades presentes em livros didáticos, Mori (2012) propõe uma forma de categorizar a abertura e participação dos alunos nas atividades experimentais. Para o autor, as atividades experimentais possuem diferentes níveis segundo o papel do livro didático/professor e dos alunos, na elaboração do problema, das hipóteses, na montagem e execução da atividade experimental, e no estabelecimento das conclusões.

Em uma aproximação da categorização de Mori (2012) aos tipos de atividades experimentais discutidos por Araújo e Abib (2013), elaboramos a Figura 1, apresentada a seguir, que sintetiza os níveis de investigação da atividade experimental presentes em livros didáticos:

Figura 1 - Níveis de participação em atividades experimentais em livros didáticos

\begin{tabular}{|c|c|c|c|c|c|c|}
\cline { 2 - 7 } \multicolumn{1}{c|}{} & \multicolumn{3}{c|}{ Niveis de participação e de abertura em atividades experimentais em livros didáticos } \\
\cline { 2 - 8 } & $\begin{array}{c}\text { Atividades de } \\
\text { Demonstração }\end{array}$ & \multicolumn{2}{c|}{ Atividades de verificação } & \multicolumn{2}{c|}{ Atividades de investigação } \\
\hline Etapa da atividade experimental & I & II & III & IV & V & VI \\
\hline Elaboração do problema ou situação Problema & Livro didático & Livro didático & Livro didático & Livro didático & Livro didático & Alunos \\
\hline Elaboração de hipóteses & Livro didático & Livro didático & Livro didático & Livro didático & Alunos & Alunos \\
\hline Elaboração do plano de trabalho & Livro didático & Livro didático & Livro didático & Alunos & Alunos & Alunos \\
\hline Montagem e execução do experimento & Professor & Alunos & Alunos & Alunos & Alunos & Alunos \\
\hline Tomada de dados experimentais & Professor* & Alunos** & Alunos & Alunos & Alunos & Alunos \\
\hline Elaboração de conclusões & Professor* & Alunos** & Alunos & Alunos & Alunos & Alunos \\
\hline
\end{tabular}

* O livro didático estabelece os dados que serão coletados e as conclusões, os quais são revelados e apresentados pelo professor ao executar o experimento.

** O livro didático estabelece os dados que serão coletados e as conclusões, os quais são revelados e apresentados pelos alunos ao executarem o experimento.

Fonte: elaborado pelos autores, com base em Mori (2012) e Araújo e Abib (2013).

Na Figura, é possível perceber que nas atividades experimentais de demonstração propostas por livros didáticos, os alunos assumem um papel de expectador. Já nas atividades experimentais de verificação e de investigação, notamos que quanto maior o nível de investigação (participação e abertura das atividades), maior é a participação efetiva dos alunos nas diferentes etapas.

Tendo como base as contribuições de Astolfi et al. (1997), Mori (2012) e Araújo e Abib (2013), assumimos em nosso estudo que uma atividade experimental pode se configurar como investigativa somente quando: (i) há uma situação problema, sendo ela proposta ou elaborada pelos alunos ou não; e (ii) há a participação dos alunos em todas as etapas da atividade experimental proposta, desde a interpretação/elaboração da situação problema até a conclusão. Tais aspectos foram elencados em nosso estudo como basilares para analisar atividades experimentais propostas em livros didáticos de ciências direcionados aos anos iniciais do Ensino Fundamental (EF I). 


\section{PERCURSO METODOLÓGICO}

Este trabalho possui cunho qualitativo e interpretativo, sendo desenvolvido segundo duas etapas principais: (i) seleção de materiais de análise e (ii) análise dos dados.

Para a seleção dos materiais a serem analisados e como parte do recorte de pesquisa que aqui apresentamos, foi definido um conjunto de critérios, descritos a seguir:

- verificação das coleções de ciências direcionadas aos anos iniciais do ensino fundamental, aprovadas no PNLD 2019;

- levantamento em pelo menos três escolas da região de São Carlos-SP, contexto mais próximo dos pesquisadores, de coleções aprovadas no PNLD 2019 utilizadas pelos professores e/ou alunos e escolhidas para o uso em sala de aula;

- seleção de coleção(ões) que fosse(m) utilizada(s) em todas as escolas consultadas;

- na(s) coleção(ões) utilizada(s) em todas as escolas, selecionar atividades experimentais que estivessem presentes em livros do $5^{\circ}$ ano e que tratassem dos conteúdos de propriedades físicas dos materiais e/ou separação de misturas.

A escolha a partir de escolas da região de São Carlos-SP ocorreu a partir de nosso interesse em buscar um retrato restrito/localizado, sem que houvesse qualquer intenção de generalização das conclusões da pesquisa para outros contextos. Ainda que localizado, acreditamos que o estudo traz contribuições para a discussão a qual nos dedicamos, sobre as propostas de experimentos em livros didáticos. Destaca-se ainda que a escolha por três escolas ocorreu de forma aleatória, entre aquelas escolas localizadas na região central ou próxima à região central da cidade.

Com relação à escolha por livros do $5^{\circ}$ ano, optamos por essa restrição por considerar que nesse nível de ensino as atividades experimentais poderiam explorar mais o potencial investigativo, tendo em vista a fase de desenvolvimento em que muitos alunos poderiam se encontrar: em uma transição de uma fase de heteronomia para uma fase de autonomia. Ainda que a compreensão de tais fases não servisse de elemento teórico que subsidiasse as análises, reconhecer as fases nos dá indicação sobre o recorte que poderíamos fazer em nosso estudo. Com relação à escolha por atividades relacionadas com os conteúdos de propriedades físicas dos materiais e/ou separação de misturas, ocorreu por entendermos que estes tópicos possuem uma estreita relação com a Química, uma ciência que possui uma relevância técnica e experimental que, a nosso ver, é maior do que na Física, na Biologia e na Geociências.

Após a definição dos documentos que seriam verificados, a análise foi feita a partir dos referenciais teóricos elencados, que tratam das atividades experimentais investigativas. A análise consistiu em (i) verificar a natureza do problema posto nas atividades experimentais (resolução de problema, problema aberto ou situação problema) e (ii) inferir sobre os níveis de investigação e de quem ou o que (alunos, professor e Livro didático) seriam os responsáveis por desenvolver os passos das atividades. 


\section{RESULTADOS E DISCUSSÕES}

Conforme o Guia do PNLD 20194 , o qual apresenta os critérios estabelecidos para avaliação das obras aprovadas e as resenhas das coleções aprovadas, 14 coleções foram aprovadas. A partir do contato com três escolas da cidade de São Carlos-SP, verificou-se quais coleções, entre as aprovadas, eram utilizadas em cada escola. Um total de seis coleções eram utilizadas nas três escolas consultadas, seja enquanto material de consulta para professores e alunos ou como livros didáticos efetivamente utilizados nas aulas. Restringindo-se aos livros do $5^{\circ}$ ano do Ensino Fundamental, apresentamos na Tabela 1, a seguir, a quantidade de atividades experimentais propostas em cada uma das coleções.

Tabela 1 - Quantidade de atividades experimentais nos livros de $5^{\circ}$ ano das coleções utilizadas nas escolas.

\begin{tabular}{|l|c|c|c|c|c|c|c|}
\cline { 2 - 8 } \multicolumn{1}{c|}{} & \multicolumn{9}{c|}{ Coleção } & \multirow{2}{*}{ Total } \\
\cline { 2 - 9 } \multicolumn{1}{c|}{} & A & B & C & D & E & F & \\
\hline Quantidade de atividades experimentais propostas & 16 & 12 & 18 & 15 & 13 & 10 & 84 \\
\hline
\end{tabular}

Fonte: elaborado pelos autores

Considerando que apenas uma coleção era utilizada nas três escolas consultadas (coleção C), das 84 atividades experimentais propostas nos livros de $5^{\circ}$ ano das seis coleções, reduzimos o nosso olhar para 18 propostas de atividades experimentais. Tendo em vista a escolha, em nosso recorte, pelos conteúdos de propriedades físicas dos materiais e separação de misturas, reduzimos o nosso material a ser analisado a quatro propostas de atividades experimentais. Das quatro atividades experimentais, três delas tratavam das propriedades físicas dos materiais, enquanto uma delas abordava o tema da separação de misturas.

Vale destacar que as três atividades que tratavam do mesmo tópico eram apresentadas no livro didático como sendo uma atividade dividida em três partes. Contudo, como a nosso ver havia uma descontinuidade de objetivos, materiais e ações entre as partes da atividade experimental, classificamos como três atividades experimentais distintas desde o início do levantamento de atividades nos livros didáticos.

A análise de cada atividade experimental é feita separadamente, a seguir:

\section{Atividade 1 - "Testando materiais" (A forma afeta a flutuação?)}

$\mathrm{Na}$ atividade, é proposto que diferentes objetos sejam colocados em uma vasilha com água, para que se verifique se a forma de um objeto pode interferir em sua flutuação. A atividade parte de dois questionamentos chave (Quadro 2):

4 Disponível em: https://pnld.nees.com.br/pnld_2019/componente-curricular/ciencias. Acesso em 14 nov 2019. 
Quadro 2 - Perguntas iniciais da atividade 1.

Por que um clipe feito de material metálico afunda em um copo com água e um navio cargueiro flutua no mar?

Como a forma de um objeto pode afetar sua capacidade de flutuar?

Fonte: Livro do $5^{\circ}$ ano da coleção $\mathrm{C}$

Para responder a essas perguntas, a atividade indica uma série de materiais, com destaque para a massa de modelar, que poderia se moldada na forma de bola e de barcos, para verificar em que situações flutuaria. A atividade apresenta um roteiro fechado, com uma série de passos a serem executados, indicando ao final uma tabela para ser preenchida com a marcação sobre cada barco (flutua ou afunda). O Quadro 3 apresenta o roteiro experimental:

Quadro 3 - Roteiro experimental da atividade 1.

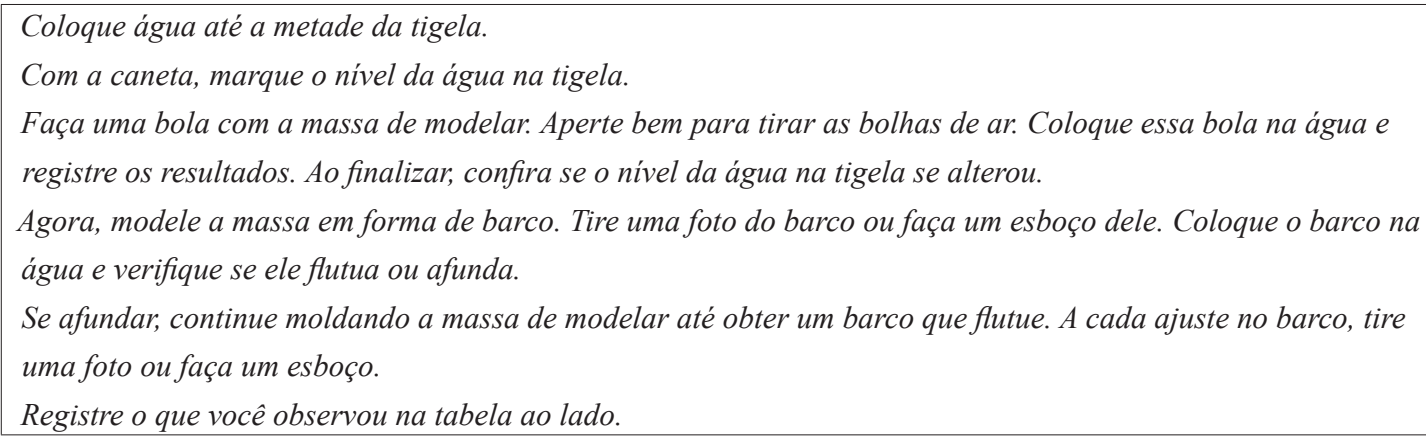

Fonte: Livro do $5^{\circ}$ ano da coleção C

Com relação às perguntas postas no início da atividade, percebemos que: há um enigma que de fato precisa ser resolvido; a situação pode levar a novos questionamentos e ideias; a solução está ao alcance dos alunos; e há um problema associado a um obstáculo de aprendizagem a ser superado, que seria a ideia de que o tipo de material utilizado, por si só, poderia fazer com que o objeto flutuasse ou não. Neste sentido, nos termos de Astolfi et al. (1997), as perguntas presentes na atividade poderiam assumir um papel de uma situação problema, a depender de como, de fato, seria utilizada no decorrer da atividade.

Contudo, apoiando-se na perspectiva de Ricardo (2010), percebemos que as perguntas carecem de mais elementos que permitam uma efetiva relação contextual com a realidade dos alunos. Não há indicações, seja no livro do aluno como no material do professor, de situações mais concretas e que cotidianamente poderiam ser vivenciadas pelos alunos. Neste sentido, há perguntas fracamente contextualizadas, de modo que um desenvolvimento e aprofundamento mais efetivo da situação posta dependeria de um olhar e ações mais críticos do professor, propondo novas discussões e perguntas que melhor relacionasse a situação com aspectos da vivência dos alunos, de modo a contribuir para que os alunos se envolvam em uma discussão coletiva sobre os resultados obtidos e os procedimentos executados, o que levaria ao conhecimento científico.

Ao analisar as demais características da proposta de atividade experimental, percebemos, contudo que: os procedimentos a serem executados são definidos na proposta e descritos enquanto um 
roteiro fechado; não há indicações de elaborações de hipóteses que poderiam ser verificadas coletivamente; não há indicações sobre debates envolvendo toda a turma e não há indicações de um reexame dos passos percorridos, de forma a permitir aos alunos executar os procedimentos sem que haja uma conscientização sobre os motivos que os levam a fazê-los.

Diante do exposto, assumimos que o problema posto representado nas perguntas, ainda que apresente algumas características que poderiam levá-lo a ser definido como uma situação problema, reúne muitas características que o situariam com uma atividade experimental de resolução de problema não contextualizada, segundo o definido por Astolfi et al. (1997) e Ricardo (2010).

Quanto ao nível de participação dos alunos, baseando-se em Mori (2012), reconhecemos que havia uma participação prevista limitada. Com relação ao problema, a proposta de atividade experimental já o traz elaborado, sem que caiba ao professor ou ao aluno trazê-lo. Sobre a elaboração de hipóteses, não há indicações sobre quem elaboraria e em que momentos, de modo que classificamos como algo indefinido. Já o plano de trabalho da atividade experimental é definido pelo próprio livro didático, conforme exposto no Quadro 3, ainda que a montagem dos experimentos seja feita pelos próprios alunos. As observações e coleta de dados são previstas que sejam feitas também pelos alunos. Contudo, sobre as conclusões, ainda que haja a indicação para que sejam feitas pelos alunos, ela se resume ao preenchimento de uma tabela, permanecendo uma indefinição sobre o aprofundamento nas conclusões. O Quadro 4 apresenta um resumo do papel do aluno, professor ou livro didático em cada uma das etapas do procedimento experimental.

Quadro 4 - Resumo da análise da atividade 1, quanto ao nível de investigação e a relação entre as etapas do procedimento $\mathrm{X}$ quem/o que propõe ou executa.

\begin{tabular}{|l|l|}
\hline \multicolumn{1}{|c|}{ Etapas do procedimento experimental } & Quem ou o que propõe/executa \\
\hline Elaboração de questão inicial, problema ou situação problema & Livro didático \\
\hline Elaboração de hipóteses & Indefinido \\
\hline Elaboração do plano de trabalho & Livro didático \\
\hline Montagem e execução do experimento & Aluno \\
\hline Tomada de dados experimentais & Aluno \\
\hline Elaboração de conclusões & Indefinido \\
\hline
\end{tabular}

Fonte: Elaborado pelos autores.

Considerando a classificação que propomos e apresentamos na Figura 1, baseada nos níveis de investigação de Mori (2012) e na classificação dos tipos de atividade experimental de Araújo e Abib 2013, entendemos que a proposta de atividade experimental "Testando os materiais" (A forma afeta a flutuação?), possui muitos elementos de uma atividade de verificação e, ademais, como os alunos executariam somente a montagem dos instrumentos e fariam as observações e coleta de dados, consistiria em um Nível II de participação. 


\section{Atividade 2 - Testando materiais (Quebra ou não quebra?)}

Esta etapa da atividade experimental é desencadeada a partir da pergunta "Quebra ou não quebra?", a qual coincide com o próprio título da atividade. Em seguida ao título, há uma descrição do que deve ser feito e uma lista de materiais a serem utilizados, e um roteiro a ser seguido.

O livro apresenta a seguinte descrição do que seria feito na atividade: "Investigar quais objetos feitos de materiais diferentes quebram com facilidade com o impacto de uma queda".

Já o roteiro experimental, apresentava uma série de passos, destacados no Quadro 5:

Quadro 5 - Roteiro experimental da atividade 2.

Formem grupos de até quatro alunos.

Em uma parede, com auxilio da fita métrica, marquem com a fita adesiva a altura de 1,30 m. Soltem dessa altura cada um dos objetos testados e observem o que acontece.

Registrem o que vocês observaram na tabela a seguir.

Fonte: Livro do $5^{\circ}$ ano da coleção C.

A tabela referida no último passo do procedimento experimental possui uma lista de objetos, distribuídos em linhas de uma coluna, com uma coluna à direita em que deve ser indicado, para cada objeto, se ele quebrou ou não quebrou.

Ao analisar se a questão que inicia a atividade (Quebra ou não quebra?) se configuraria como uma situação problema, percebemos que não há explicitamente qualquer obstáculo de aprendizagem associado. Mesmo nas orientações direcionadas ao professor (livro do professor), não há qualquer indicação sobre um possível obstáculo de aprendizagem a ser superado. Além disso, percebemos que ainda que haja uma situação concreta que possa ser testada e observada pelos alunos, ela não se constitui como um questionamento envolvendo uma situação contextual que seja familiar aos alunos. Neste sentido, o possível problema a ser solucionado se afasta da ideia de uma situação problema. Essa interpretação é corroborada por duas outras características da atividade: a abertura e os procedimentos da atividade.

Com relação a uma abertura da atividade, que permitiria o surgimento de novos questionamentos e novas elaborações de ideias, ainda que no material do aluno a atividade seja demasiadamente direcionada, no material do professor é sugerido examinar outros objetos de interesse dos alunos, o que poderia permitir uma discussão acerca de outras características dos materiais. Contudo, essa sugestão é demasiada sucinta e colocada como uma opção ao professor. Já sobre os procedimentos a serem executados, pode-se notar que há instruções predefinidas e fechadas pelo próprio livro didático para solucionar o problema posto. Neste sentido, podemos assumir que, com relação aos procedimentos, a atividade envolve um roteiro fechado característico de uma resolução de problemas e não uma situação problema. Além disso, não há uma indicação sobre momentos na realização da atividade envolvendo o levantamento de hipóteses e o debate científico entre os alunos, indicações estas que sinalizariam uma situação problema em processo de solução. 
Em uma seção do livro, próximo à atividade experimental, intitulada "Para você responder", há a indicação de questões que podem facilitar a conclusão e validação do que pode ser observado pelos alunos. Contudo, na proposta e no material do professor não é mencionado o papel do professor na atividade. Além disso, não há indicações de uma atividade reflexiva em torno dos procedimentos experimentais.

Em relação ao nível de participação dos alunos na proposta de atividade experimental, pode-se concluir que a elaboração do problema e o plano de trabalho são fornecidos pelo livro didático, de modo que os alunos apenas devem seguir o que é indicado.

Já em relação à montagem do material e a observação e coleta de dados, propõe-se que sejam realizadas pelos alunos. Destaca-se também, que há uma indefinição em relação à elaboração e o levantamento de hipóteses e em relação à conclusão da atividade experimental, de modo que o livro didático não explicita se estas ações ficariam a cargo do professor ou do aluno. O Quadro 6 apresenta um resumo da relação entre as etapas do procedimento experimental e quem propõe/executa.

Quadro 6 - Resumo da análise da atividade 2, quanto ao nível de investigação e a relação entre as etapas do procedimento $\mathrm{X}$ quem/o que propõe ou executa.

\begin{tabular}{|l|l|}
\hline \multicolumn{1}{|c|}{ Etapas do procedimento experimental } & Quem ou o que propõe/executa \\
\hline Elaboração de questão inicial, problema ou situação problema & Livro didático \\
\hline Elaboração de hipóteses & Indefinido \\
\hline Elaboração do plano de trabalho & Livro didático \\
\hline Montagem e execução do experimento & Aluno \\
\hline Tomada de dados experimentais & Aluno \\
\hline Elaboração de conclusões & Indefinido \\
\hline
\end{tabular}

Fonte: Elaborado pelos autores.

Assim como ocorre em relação à proposta da atividade 1, a atividade 2 possui um baixo nível de participação dos alunos, os quais executariam somente a montagem dos instrumentos e fariam as observações e coleta de dados, situando a proposta como uma atividade experimental de Nível II de participação.

\section{Atividade 3 - Testando materiais (Estica ou não estica?)}

Assim como na atividade anteriormente destacada, esta etapa da atividade experimental é também desencadeada a partir de uma pergunta, "Estica ou não estica?", que consiste no próprio título da atividade. Após o título, também há uma descrição do que deve ser feito: "Investigar quais objetos feitos de materiais diferentes esticam sem romper quando submetidos a uma força".

Após a instrução do que será feito, também há uma lista de materiais a serem utilizados e um roteiro a ser seguido, o qual apresentamos no Quadro 7: 
Quadro 7 - Roteiro experimental da atividade 3.

Formem grupos de até quatro alunos.
Peguem cada um dos objetos pelas extremidades e tentem esticá-los. Observem o que acontece.
Anotem o que vocês observaram na tabela a seguir.

Fonte: Livro do $5^{\circ}$ ano da coleção C.

A tabela referida no último passo do procedimento experimental também possui uma lista de objetos, como na atividade experimental anterior, sendo que nas linhas da coluna à direita da lista de objetos deve ser indicado se cada objeto estica ou não estica.

Ao analisarmos a atividade, reconhecemos que o problema posto, ainda que envolva uma situação concreta, constitui-se como algo simples e pouco problematizador. No material do professor é indicada a possibilidade de serem feitos novos questionamentos e elaboração de ideias a partir dos conhecimentos prévios dos alunos acerca do assunto, conforme destacado no trecho em destaque no Quadro 8. Contudo, não há um direcionamento claro, ao professor, sobre como esse levantamento de objetos do cotidiano poderiam ser utilizados como um elemento problematizador, de modo a potencializar um caráter investigativo na atividade.

Quadro 8 - Destaque do material do professor.

Antes de iniciar a atividade, pergunte aos alunos quais produtos feitos com materiais flexiveis eles conhecem e qual a importância da elasticidade para esses produtos. Comente que vários itens de vestuário, além de artigos esportivos, como roupas, tênis e bolas, são feitos com materiais flexíveis, permitindo movimentos mais amplos do corpo, segurança das articulações e melhor desempenho no esporte, por exemplo. Mencione objetos presente no dia a dia dos alunos.

Fonte: Livro do $5^{\circ}$ ano da coleção C.

Ao analisarmos a atividade experimental, interpretamos que ela se assemelha a uma atividade de resolução de problemas. Por exemplo, não há na proposta indicações de momentos reservados para um debate científico ou para o levantamento de hipóteses. Além disso, os procedimentos são pré-definidos e fechados, sem muita abertura para adaptações pelos alunos. Não há, também, ações previstas para a superação de algum obstáculo de aprendizagem e nem momentos reservados para uma ação reflexiva que pudesse levar os alunos a se conscientizar sobre os procedimentos desenvolvidos.

Em relação ao nível de participação dos alunos na proposta de atividade experimental, semelhante às demais atividades analisadas, concluímos que a elaboração do problema e o plano de trabalho são fornecidos pelo livro didático, cabendo aos alunos apenas executar os passos indicados. Em relação à montagem do material e à observação e coleta de dados, até propõe-se que sejam realizadas pelos alunos, mas seguindo passos bem definidos e com pouca abertura para momentos de debate e maiores reflexões.

O livro didático não explicita se a elaboração e o levantamento de hipóteses, bem como as conclusões, seriam feitos pelo professor ou pelos alunos. O Quadro 9 apresenta um resumo da relação entre as etapas do procedimento experimental e quem propõe/executa. 
Quadro 9 - Resumo da análise da atividade 3, quanto ao nível de investigação e a relação entre as etapas do procedimento X quem/o que propõe ou executa.

\begin{tabular}{|l|l|}
\hline \multicolumn{1}{|c|}{ Etapas do procedimento experimental } & Quem ou o que propõe/executa \\
\hline Elaboração de questão inicial, problema ou situação problema & Livro didático \\
\hline Elaboração de hipóteses & Indefinido \\
\hline Elaboração do plano de trabalho & Livro didático \\
\hline Montagem e execução do experimento & Aluno \\
\hline Tomada de dados experimentais & Aluno \\
\hline Elaboração de conclusões & Indefinido \\
\hline
\end{tabular}

Fonte: Elaborado pelos autores.

\section{Atividade 4 - Separação de misturas}

A atividade sobre o tema da separação de misturas possui algumas diferenças em relação às demais atividades aqui apresentadas. Ela possui um título simples (Separação de misturas), porém sem ser na forma interrogativa. Em seguida, há a indicação sobre o que seria feito: "Verificar uma forma de separar misturas".

Após, é apresentada uma lista de matérias e um conjunto de passos a serem seguidos, destacados no quadro 10 :

Quadro 10 - Roteiro experimental da atividade 4.

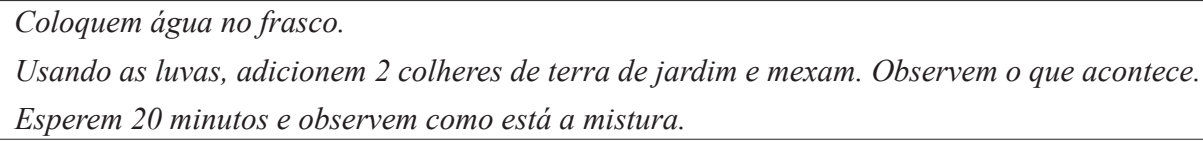

Em seguida, há quatro perguntas, às quais devem ser respondidas pelos alunos, conforme destacado no quadro 11.

Quadro 11 - Perguntas da atividade 4, a serem respondidas pelos alunos.

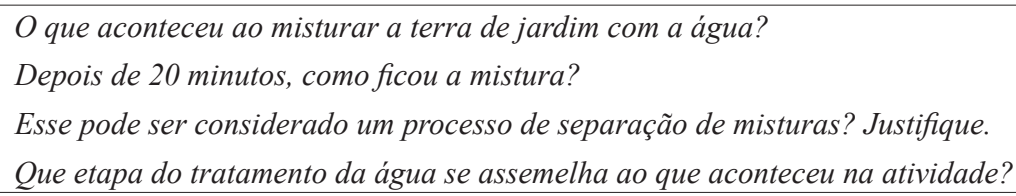

Ao analisar a proposta de atividade experimental, verificamos que não há a apresentação de qualquer problema, ou mesmo questionamento inicial. Mesmo os questionamentos presentes no Quadro 11, eles parecem cumprir uma função de complemento do roteiro experimental, enquanto campos a serem preenchidos.

Podemos verificar também que, por mais que a atividade envolva procedimentos que podem ser desenvolvidos pelos alunos, não há a indicação de uma situação contextual concreta. Além disso, os procedimentos são definidos pelo próprio livro didático, não há obstáculos de aprendizagem 
explicitados, não há enigmas a serem solucionados, não há condições explícitas para a condução de novos questionamentos e ideias e para a elaboração de hipóteses, não há indicações de momentos para o debate científico entre os alunos e não é indicado qualquer processo de validação e os papeis dos alunos e professor nesta ação de forma reflexiva.

Assim, consideramos que a atividade se aproxima de uma resolução de problemas a partir de uma atividade experimental, mas havendo um agravante de não ser indicado, de fato, um problema ou questão inicial.

Em relação ao nível de participação dos alunos na proposta de atividade experimental, da mesma forma que em outras propostas de atividade analisadas, não há um problema definido, bem como uma indicação do papel do professor ou dos alunos na conclusão da atividade. Também não há qualquer indicação de hipóteses ou momentos para o levantamento destas.

Embora caiba aos alunos executar a montagem do material e observar e coletar os dados, o plano de trabalho é definido pelo livro didático. Assim, os alunos apenas executam passos pré-definidos da atividade experimental.

Quadro 12 - Resumo da análise da atividade 4, quanto ao nível de investigação e a relação entre as etapas do procedimento X quem/o que propõe ou executa.

\begin{tabular}{|l|l|}
\hline \multicolumn{1}{|c|}{ Etapas do procedimento experimental } & Quem ou o que propõe/executa \\
\hline Elaboração de questão inicial, problema ou situação problema & Indefinido \\
\hline Elaboração de hipóteses & Indefinido \\
\hline Elaboração do plano de trabalho & Livro didático \\
\hline Montagem e execução do experimento & Aluno \\
\hline Tomada de dados experimentais & Aluno \\
\hline Elaboração de conclusões & Indefinido \\
\hline
\end{tabular}

Fonte: Elaborado pelos autores.

Observamos que essa atividade também possui um nível menor de participação dos alunos, os quais se evolvem somente na montagem experimental e na observação e coleta de dados, o que nos leva a classificá-la como uma atividade experimental de nível II. Vale destacar, contudo, o fato dessa proposta de atividade não possuir um problema exposto, o que está previsto em todas as categorias definidas por Mori (2012), mesmo aquelas de menor nível investigativo.

\section{CONSIDERAÇÕES FINAIS}

Neste artigo, trouxemos um recorte de uma pesquisa mais ampla que buscou investigar propostas de atividades experimentais presentes em livros didáticos de ciências do primeiro ciclo do Ensino Fundamental, aprovados no Programa Nacional do Livro Didático e utilizados em escolas da região de São Carlos-SP. Desde as contribuições da literatura sobre atividades investigativas, buscamos verificar o nível investigativo das propostas das atividades experimentais, tendo como 
balizadores a noção de situação problema, os tipos de atividades experimentais, e os níveis de participação relacionados com o nível investigativo das atividades.

A partir dos resultados e das análises apresentadas, concluímos que, no recorte aqui apresentado, as propostas de atividade experimental apresentam um baixo grau de investigação, sem situações problematizadoras que envolvam os alunos, com roteiros fechados a serem seguidos, e com uma participação limitada, passiva e em certa medida mecânica dos alunos. As atividades possuem pouca abertura para a ação criativa dos alunos e, mesmo ao professor, há uma atuação esperada limitada, que se diferencia daquela função mediadora de debates e ideias, esperadas em uma atividade investigativa a ser realizada em sala de aula.

Por fim, vale destacar que os resultados obtidos não podem ser generalizados, mas contribuem, a nosso ver, com a discussão sobre o papel das atividades experimentais propostas em livros didáticos em apresentar a ciência como um processo coletivo e criativo, assim como o papel dessas atividades na compreensão e construção de conhecimentos científicos em sala de aula. Sugerimos que novos estudos sejam realizados, focando outras obras e atividades.

\section{REFERÊNCIAS}

AMARAL, I. A. do. Currículo de ciências; das tendências clássicas aos movimentos atuais de renovação. In: Barreto, Elba de Sá (org.). Os currículos do ensino fundamental para as escolas brasileiras. Campinas: Autores Associados, São Paulo: FCG, 2000, p. 201-232.

ARAÚJO, M. S. T; ABIB, M. L. V. S. Atividades Experimentais no Ensino de Física: diferentes enfoques, diferentes finalidades. Revista Brasileira de Ensino de Física, v. 25, n. 2, p. 176-194, 2003.

ASTOLFI, J-P; DAROT, E; GINSBURGER-VOGEL, Y.; TOUISSAINT, J. As palavras-chave da didática das Ciências: referências, definições, bibliografias. Lisboa: Instituto Piaget, 1997.

BRAGANÇA, A. As políticas públicas para o livro e a leitura no Brasil: o instituto Nacional do Livro (1937-1967). Matrizes, v. 2, n. 2, p. 221-246, 2009.

BRASIL. Decreto-lei Nº93, de 21 de dezembro de 1937, que cria o Instituto Nacional do Livro.

BRASIL. Decreto-lei N 1006, de 30 de dezembro de 1938, que estabelece as condições de produção, importação e utilização do livro didático.

BRASIL. Decreto-lei N 1006, de 30 de dezembro de 1938, que estabelece as condições de produção, importação e utilização do livro didático. 
BRASIL. Decreto $\mathbf{n}^{0}$ 91.542, de 19 de agosto de 1985, que institui o Programa Nacional do Livro Didático, dispõe sobre sua execução e dá outras providências.

BRASIL. Ministério da Educação. Programa Nacional do Livro e do Material Didático. Brasília: MEC/SEB, 2008.

BRASIL. Ministério da Educação. Edital de convocação para o processo de inscrição e avaliação de obras didáticas para o Programa Nacional do Livro Didático PNLD 2016. Brasília, 2014.

BRASIL. Ministério da Educação. Programa Nacional do Livro e do Material Didático. Brasília: MEC/SEB, 2018.

CHALMERS, A.F. O que é ciência, afinal? São Paulo, Brasiliense, 1993.

FERNANDES, R. C. A; MEGID NETO, J. Inovações Pedagógicas no Ensino de Ciências dos Anos Iniciais: um estudo a partir de pesquisas acadêmicas brasileiras (1972-2012). In: Encontro Nacional de Pesquisa em Ensino de Ciências, XI, 2017, Florianópolis: ENPEC, 2017.

FRACALANZA, H. E.; MEGID NETO, J. (orgs.). O livro didático de Ciências no Brasil. Campinas: Editora Komedi, 2006.

FILGUEIRAS, J. M. Os processos de avaliação de livros didáticos no Brasil (1938-1984). Tese (Doutorado em educação), São Paulo, Pontifícia Universidade Católica de São Paulo. 2011.

FILGUEIRAS, J. M. As avaliações dos livros didáticos na Comissão Nacional do Livro Didático: a conformação dos saberes escolares nos anos 1940. Revista Brasileira de História da Educação, v. 13, n. 1 (31), p. 159-192, 2013.

HODSON, D. Hacia um enfoque más crítico del trabajo de laboratorio. Enseñanza de las Ciencias, v. 12 , n. 13 , p. 299-313, 1994.

MELLADO, V. ; CARRACEDO, D. Contribuciones de la filosofía de la ciencia a la didáctica de las ciencias. Enseñanza de las ciências, v. 11, n. 3, 1993.

MIZUKAMI, M. G. N. Ensino: As abordagens do processo. São Paulo: EPEU, 1986. 
MORI, R.C.; CURVELO, A. A. S. A polissemia da palavra "Experimentação" e a Educação em Ciências.

Química Nova na Escola. v. 39, n. 3, p. 291 -304, 2017.

MORI, R.C. O grau de participação requerido dos estudantes em atividades experimentais de Química: Uma análise dos livros de Ciências aprovados no PNLD/2007. Revista Brasileira de Pesquisa em Educação em Ciências. v. 12, n. 3, 2012.

OLIVEIRA, J. R. S. Contribuições e abordagens das atividades experimentais no ensino de ciências: reunindo elementos para a prática docente. Acta Scientiae. v. 12, n. 1, 2010.

PÉREZ, D. G.; MONTORO, I. F.; ALÍS, J. C.; CACHAPUZ, A.; PRAIA, J. Para uma imagem não deformada do trabalho científico. Ciência \& Educação, v. 7, n. 2, p. 125-153, 2001.

PIETROCOLA, M. Construção da realidade: o realismo científico de Mário Bunge e o ensino de ciências através de modelos. Investigações em ensino de ciências, v. 4, n. 3, p. 213-227, 1999.

RHEINBERGER, H., Gaston Bachelard and the Notion of "Phenomenotechnique". Perspectives on Science, v. 13, n. 3, 2005.

RICARDO, E. C. Educação CTSA: obstáculos e possibilidades para sua implementação no contexto escolar. Revista Ciência e Ensino. v. 1. Número Especial. 2007.

RICARDO, E. C. Problematização e contextualização no ensino de Física. In: CARVALHO, A. M. P. ; RICARDO, E. C.; SASSERON, L. H.; ABIB, M. L. V. S.; PIETROCOLA, M. Ensino de Física. São Paulo: Cengage Learning, 2010.

SILVEIRA, F. L. A filosofia de Karl Popper e suas implicações no ensino de ciência. Caderno Catarinense de Ensino de Física, v. 6, n. 2, 1989.

SUART, R.; MARCONDES, M. E. R. A manifestação de habilidades cognitivas em atividades experimentais investigativas no ensino médio de química. Ciências \& Cognição, v. 14, n. 1, 2009.

ZOMPERO, A. F.; GONÇALVES, C. E. S. G.; LABURÚ, C. E. Atividades de investigação na disciplina de Ciências e desenvolvimento de habilidades cognitivas relacionadas a funções executivas.

Ciência \& Educação, v. 23, n. 2, 2017. 